\title{
Demand for energy in Zimbabwe industries: an aggregated demand analysis
}

\author{
J C Nkomo \\ Energy Research Centre, University of Cape Town, South Africa \\ H E Goldstein \\ Department of Economics, University of Oslo, Norway
}

and more efficient estimates, provided the pooling assumptions are valid.

Because we combine cross-section and timeseries data in the estimation of regression equations, some other effects may be present in data. For this reason, we propose the 'random effects' and the 'fixed effects' frameworks. The random effects model treats the effects as randomly distributed thus providing more efficient estimates of the parameters. The fixed effects model allows for individual effects to be introduced on parameters to be estimated. We also include dummy variables in our regression equations to account for each industry within the industry group.

This paper adopts the following structure. We begin by describing the estimation procedure for the pooled model. This is followed by a discussion of the performance of the model and tests for the desirable properties of the models. The question we raised is then answered by the elasticity estimates and the implication of the results we get.

\section{Model estimation}

Once we include the dummy variables in the translog fuel-share equations, the typical error term becomes, where $i$ indexes the energy type, $k$ indexes the industry in an industry group, $t$ indexes the time period and are the fixed effects. We can then write our model as:

$$
\begin{aligned}
& \quad S_{i k t}=f_{i k}+\sum_{j=1}^{3} \gamma_{i j} \log P_{j t}+\varepsilon_{i k t} \\
& t=1,2, \ldots, T \\
& i=1,2,23=e, c, l \\
& e=\text { electricity } \\
& c=\text { coal } \\
& l=\text { liquid fuels } \\
& k=1,2, \ldots, H \text { (industries) } \\
& \varepsilon_{i k t}=\rho_{i} \varepsilon_{i k t-1}+v_{i k t}
\end{aligned}
$$


where $\left\{v_{i k t}\right\}$ are normally distributed with $E\left(v_{i k t}\right)$ and $\operatorname{cov}\left(v_{i k t}, v_{j k t}\right)=\sigma_{i j}$. In addition $v_{i k t}, v_{j i k} t^{\prime}$ are independent for $(k, t) \neq^{\prime}\left(k^{\prime}, t^{\prime}\right)$.

A number of restrictions can be imposed on the translog model, such as:

$$
\begin{aligned}
& \sum_{i} S_{i k t}=1 \\
& \sum_{i-1}^{3} \varepsilon_{i k t}=\sum_{i=1}^{3} v_{i k t}=0 \\
& \sum_{i} f_{i k}=1 \\
& \sum_{i} \gamma_{i j}=\sum_{j} \gamma_{i j}=0
\end{aligned}
$$

We will test the symmetry hypothesis

$$
\gamma_{i j}=\gamma_{j i}
$$

The restrictions under (3) allow the following equivalent reduction of the model for estimation:

$$
\begin{gathered}
S_{i k t}=f_{i k}+\gamma_{i 1} \log \left(\frac{P_{1 t}}{P_{3 t}}\right)+\gamma_{i 2} \log \left(\frac{P_{2 t}}{P_{3 t}}\right)+\varepsilon_{i k t} \\
\varepsilon_{i k t}=\rho_{i} \varepsilon_{i k t-1}+v_{i k t} \\
v_{k t}=\left(\begin{array}{l}
v_{1 k t} \\
v_{2 k t}
\end{array}\right) \sim N(0, \Omega) \\
\Omega=\left(\begin{array}{ll}
\omega_{11} & \omega_{12} \\
\omega_{21} & \omega_{22}
\end{array}\right) \\
i=1,2(=e, c) \\
k=1,2, \ldots, H \\
t=1,2, \ldots, T
\end{gathered}
$$

\section{Restricted estimation}

For the model

$$
\begin{aligned}
& Y=X^{\prime} \beta+v \\
& \operatorname{cov}(v)=\Omega
\end{aligned}
$$

with restrictions

$$
R \beta=q
$$

(where $R, q$ are known), we obtain the restricted FGLS estimator $\hat{\beta}_{r}$ for $\beta$ by modifying Greene's approach, which is based on a diagonal $\operatorname{cov}(v)=$ $\Omega$, slightly. By writing

$$
\Omega=D D^{\prime}
$$

and transforming

$$
\mathrm{Y}=\mathrm{D}^{-1} \mathrm{Y}
$$

we find

$$
\operatorname{cov} Y^{*}=D^{-1} D D^{\prime}\left(D^{\prime}\right)^{-1}=I
$$

Hence, we may continue with Greene's approach on $Y *$ and substitute

$$
Y=D Y *
$$

This gives the restricted FGLS:

$\hat{\beta}_{r}=\hat{\beta}-\left(X^{\prime} \hat{\Omega}^{-1} X\right)^{-1} R^{\prime}\left[R\left(X^{\prime} \hat{\Omega}{ }^{-1} X\right)^{-1} R^{\prime}\right]^{-1}(R \hat{\beta}-q)$

with estimated covariance matrix

$$
\begin{aligned}
& \operatorname{cov} v\left(\hat{\beta}_{r}\right)=\left(X^{\prime} \hat{\Omega}^{-1} X\right)^{-1}-\left(X^{\prime} \hat{\Omega}^{-1} X\right)^{-1} * \\
& R^{\prime}\left|R\left(X^{\prime} \hat{\Omega}^{-1} X\right)^{-1} R^{\prime}\right|^{\prime} R\left(X^{\prime} \hat{\Omega}^{-1} X\right)^{-1}
\end{aligned}
$$

\begin{tabular}{|c|c|c|c|c|c|}
\hline Industry $\mathrm{O}$ & $\begin{array}{l}\text { Dbserv- } \\
\text { ations }\end{array}$ & $\begin{array}{c}\text { Wald } \\
\text { Test }\end{array}$ & P-Value & $\hat{\gamma}_{12}-\hat{\gamma}_{21}$ & $\begin{array}{c}\text { Standard } \\
\text { error }\end{array}$ \\
\hline Mining & 115 & 1.1055 & 0.293 & -0.0372 & 0.0354 \\
\hline Foodstuff & 138 & 4.2138 & 0.040 & -0.0788 & 0.0384 \\
\hline $\begin{array}{l}\text { Bev \& } \\
\text { tobacco }\end{array}$ & 69 & 0.5056 & 0.477 & 0.0329 & 0.0463 \\
\hline Textile & 69 & 0.0226 & 0.881 & 0.0116 & 0.0771 \\
\hline Clothing & 46 & 0.1687 & 0.681 & -0.0477 & 0.1161 \\
\hline $\begin{array}{l}\text { Wood \& } \\
\text { paper }\end{array}$ & 46 & 0.936 & 0.333 & 0.087 & 0.0899 \\
\hline Chemicals & s 115 & 0.5160 & 0.473 & -0.0421 & 0.0587 \\
\hline $\begin{array}{l}\text { Non- } \\
\text { metallic }\end{array}$ & 46 & 0.0004 & 0.985 & 0.0019 & 0.0981 \\
\hline Metals & 69 & 0.0423 & 0.837 & 0.0153 & 0.0745 \\
\hline $\begin{array}{l}\text { Trans. \& } \\
\text { other }\end{array}$ & 69 & 3.3194 & 0.068 & -0.9562 & 0.0525 \\
\hline
\end{tabular}

The Wald Test for

$$
\begin{aligned}
& H_{0}: R \beta=0 \\
& H_{1}: R \beta \neq{ }^{`} q
\end{aligned}
$$

is given by

$$
W=(R \hat{\beta}-q)^{\prime}\left[R \operatorname{covv}(\hat{\beta}) R^{\prime}\right]^{-1}(R \hat{\beta}-q)
$$

Under $H_{0}, W$ is asymptotically $\chi^{2}$ - distributed with $r$ degrees of freedom.

\section{Empirical results \\ Performance of the model}

Before comparing the implied price elasticities, we first test whether or not there is loss of fit from imposing the symmetry restrictions. This is done by estimating equations with and without the symmetry restrictions, and comparing the results using a Wald Test statistic. Under the null hypotheses, this test is distributed asymptotically as chi-square with degrees of freedom equal to the number of restrictions being tested. The results of this test are reported in Table 1.

Table 1: Wald test for symmetry

We check for monotonicity by determining if the fitted values of the cost shares are positive. All the 
fitted cost shares for all the years, industries and energy types for the translog energy model are positive. We check for concavity at the observed prices in each year and for each industry by checking for a negative semi-definite Hessian matrix and by examining the signs of own-price elasticity estimates (any positive estimates of $\eta_{i i}$ or own price elasticities indicate violation of concavity). About 90 percent of our calculated Hessians are negative semi-definite. Most violations (67 percent) are in the price of coal, with the least violations (5 percent) in the price of liquid fuels.

The violation of concavity raises serious questions as to whether the observed data (for those industries with violations) are consistent with the hypothesis of cost minimisation. The reason for the rejection of concavity may range from the quality of data to the level of aggregation applied. It should be understood that the translog is only any approximation to the true cost function, and that the rejection of cost-minimising behaviour may reflect the inaccuracy of the approximation rather than the compatibility of the restrictions with producer behaviour. As these results reflect that the maintained hypothesis of instantaneous adjustment to price changes is too restrictive, one may argue that the violations obtained are in part a reflection of the static specification of the model.

\section{Elasticity estimates}

Parameter estimates $\left(\gamma_{i j}\right)$ in Table 2 have an economic interpretation. They are share elasticities, and explain how cost shares respond to changes in price. Positive coefficients with respect to price mean that the cost shares increase with an increase in price. If the coefficient is zero, then cost share is independent of price. Negative values, on the other hand, imply that cost shares decrease with the proportional increase in the price of other inputs.

Using parameter estimates in Table 2 together with cost share data, we calculate the elasticities of demand. Own-elasticity of demand is defined by

$$
\begin{gathered}
\eta_{i i}=\left[\frac{\gamma_{i i}}{S_{i}}+S_{i}-1\right]=\left[\frac{\gamma_{i i}+S_{i}^{2}-S_{i}}{S_{i}}\right] \\
i=e, c, l
\end{gathered}
$$

and cross-price elasticity of demand by

$$
\begin{gathered}
\eta_{i j}=S_{j}\left[\frac{\gamma_{i i}}{S_{i} S_{j}}+1\right]=\left[\frac{\gamma_{i i}+S_{i} S_{j}}{S_{i}}\right] \\
\mathrm{i} \neq \mathrm{j} \\
i, j=e, c, l \\
\eta_{i j} \neq \eta_{j i}
\end{gathered}
$$

In Tables 3 and 4 we present, as representative results, elasticities calculated at mean values of energy cost shares. An inspection of elasticity esti-

\begin{tabular}{|c|c|c|c|c|c|c|c|}
\hline Parameters & $\gamma_{c c}$ & $\gamma_{e e}$ & $\gamma_{l l}$ & $\gamma_{c e}$ & $\gamma_{c l}$ & $\gamma_{e l}$ & $\begin{array}{c}\text { No. of } \\
\text { observations }\end{array}$ \\
\hline Mining & $\begin{array}{l}0.0225 \\
(1.351) \\
\end{array}$ & $\begin{array}{l}0.0556 \\
(2.044) \\
\end{array}$ & $\begin{array}{l}0.0486 \\
(1.941) \\
\end{array}$ & $\begin{array}{l}-0.0147 \\
(-1.068)\end{array}$ & $\begin{array}{l}-0.0078 \\
(-0.491)\end{array}$ & $\begin{array}{l}-0.0408 \\
(-1.812) \\
\end{array}$ & 115 \\
\hline Foodstuffs & $\begin{array}{l}0.1033 \\
(3.769)\end{array}$ & $\begin{array}{l}0.1621 \\
(7.150)\end{array}$ & $\begin{array}{l}0.0657 \\
(1.437)\end{array}$ & $\begin{array}{l}-0.0998 \\
(-5.733)\end{array}$ & $\begin{array}{l}-0.0034 \\
(-0.115)\end{array}$ & $\begin{array}{l}-0.0623 \\
(-2.230)\end{array}$ & 138 \\
\hline $\begin{array}{l}\text { Beverages } \\
\text { and tobacco }\end{array}$ & $\begin{array}{l}0.1054 \\
(2.816)\end{array}$ & $\begin{array}{l}0.0992 \\
(3.769)\end{array}$ & $\begin{array}{l}0.0433 \\
(0.793)\end{array}$ & $\begin{array}{l}-0.0806 \\
(-3.537)\end{array}$ & $\begin{array}{l}-0.0247 \\
(-0.640)\end{array}$ & $\begin{array}{l}-0.0186 \\
(-0.588)\end{array}$ & 69 \\
\hline Textiles & $\begin{array}{l}-0.0381 \\
(-0.686)\end{array}$ & $\begin{array}{l}0.0489 \\
(1.034)\end{array}$ & $\begin{array}{l}0.0379 \\
(0.532)\end{array}$ & $\begin{array}{l}0.0135 \\
(0.351)\end{array}$ & $\begin{array}{l}0.0246 \\
(0.476)\end{array}$ & $\begin{array}{l}-0.0625 \\
(-1.299)\end{array}$ & 69 \\
\hline $\begin{array}{l}\text { Clothing and } \\
\text { footwear }\end{array}$ & $\begin{array}{l}0.1089 \\
(2.243)\end{array}$ & $\begin{array}{l}0.0593 \\
(0.815)\end{array}$ & $\begin{array}{l}-0.0268 \\
(-0.220)\end{array}$ & $\begin{array}{l}-0.0975 \\
(-2.604)\end{array}$ & $\begin{array}{l}-0.0114 \\
(-0.204)\end{array}$ & $\begin{array}{l}0.0382 \\
(0.429)\end{array}$ & 46 \\
\hline $\begin{array}{l}\text { Wood and } \\
\text { paper }\end{array}$ & $\begin{array}{l}-0.0408 \\
(-0.564) \\
\end{array}$ & $\begin{array}{l}0.1644 \\
(3.212)\end{array}$ & $\begin{array}{l}0.0253 \\
(0.238)\end{array}$ & $\begin{array}{l}-0.4918 \\
(-1.117)\end{array}$ & $\begin{array}{l}0.0899 \\
(1.203)\end{array}$ & $\begin{array}{l}-0.1152 \\
(-1.842) \\
\end{array}$ & 46 \\
\hline $\begin{array}{l}\text { Chemical } \\
\text { products }\end{array}$ & $\begin{array}{l}-0.0512 \\
(-0.358)\end{array}$ & $\begin{array}{l}0.0862 \\
(2.491)\end{array}$ & $\begin{array}{l}-0.0555 \\
(-0.888)\end{array}$ & $\begin{array}{l}-0.0452 \\
(-1.002)\end{array}$ & $\begin{array}{l}0.0964 \\
(1.879)\end{array}$ & $\begin{array}{l}-0.0410 \\
(-1.159)\end{array}$ & 115 \\
\hline $\begin{array}{l}\text { Non- } \\
\text { metallic }\end{array}$ & $\begin{array}{l}0.0064 \\
(0.111) \\
\end{array}$ & $\begin{array}{l}0.0747 \\
(1.477) \\
\end{array}$ & $\begin{array}{l}0.0739 \\
(1.636)\end{array}$ & $\begin{array}{l}-0.0036 \\
(-0.074)\end{array}$ & $\begin{array}{l}-0.0028 \\
(-0.074) \\
\end{array}$ & $\begin{array}{l}-0.0711 \\
(-2.689) \\
\end{array}$ & 46 \\
\hline $\begin{array}{l}\text { Metals } \\
(0.664)\end{array}$ & $\begin{array}{l}0.0465 \\
(4.159)\end{array}$ & $\begin{array}{c}0.1421 \\
(-2.279)\end{array}$ & $\begin{array}{l}-0.0240 \\
(-2.972)\end{array}$ & $\begin{array}{c}-0.1063 \\
(0.861)\end{array}$ & $\begin{array}{c}0.0597 \\
(-0.858)\end{array}$ & -0.0358 & 69 \\
\hline $\begin{array}{l}\text { Transport } \\
\text { and other }\end{array}$ & $\begin{array}{l}0.0394 \\
(1.078)\end{array}$ & $\begin{array}{l}0.0920 \\
(3.064)\end{array}$ & $\begin{array}{l}-0.0375 \\
(-0.629)\end{array}$ & $\begin{array}{l}-0.0845 \\
(-3.463)\end{array}$ & $\begin{array}{l}0.0451 \\
(1.186)\end{array}$ & $\begin{array}{l}-0.0075 \\
(-0.200)\end{array}$ & 69 \\
\hline
\end{tabular}
mates shows that the model generally obeys the property of linear homogeneity in fuel prices since $\Sigma_{j} \eta_{i j}=0$ with slight discrepancies attributed to rounding of figures to the nearest final digit.

Table 2: Translog parameter estimates Zimbabwe mining and manufacturing industries 
Table 3: Own price elasticities of demand

\begin{tabular}{|c|c|c|c|}
\hline & $\eta_{E E}$ & $\eta_{C C}$ & $\eta_{L L}$ \\
\hline \multicolumn{4}{|l|}{ Mining } \\
\hline Chrome & -0.2903 & -1.1693 & -0.6475 \\
\hline Copper and nickel including smelting & -0.2225 & -0.9592 & -0.7697 \\
\hline Gold & -0.1663 & -1.2703 & -0.7479 \\
\hline Asbestos & -0.1583 & -1.1577 & -0.7663 \\
\hline Other mining & -0.3191 & -1.3526 & -0.5935 \\
\hline \multicolumn{4}{|l|}{ Foodstuffs } \\
\hline Slaughtering and processing of meat & -0.1291 & -1.3939 & -1.3913 \\
\hline Canning and preserving fruit and vegetables & -0.1884 & -0.9531 & -1.1470 \\
\hline Grain mill products and animal foods & -0.1882 & -1.5781 & -0.9370 \\
\hline Chocolate and sugar confectionary & -0.1939 & -1.1939 & -1.0530 \\
\hline Dairy and food products & -0.1414 & -0.8601 & -1.0956 \\
\hline \multicolumn{4}{|l|}{ Beverages and tobacco } \\
\hline Beer, wine and spirits & -0.3587 & -0.3461 & -0.5381 \\
\hline Tobacco products inc. post-auction grading and packing & -0.3536 & -0.3505 & -0.5608 \\
\hline \multicolumn{4}{|l|}{ Textiles and cotton } \\
\hline Cotton, ginning, spinning, weaving finishing textiles & -0.3196 & -0.7120 & -0.3112 \\
\hline Knitted products, rope and cordage & -0.3931 & -0.6567 & -0.3403 \\
\hline Other textile products & -0.3525 & -0.7373 & -0.3909 \\
\hline \multicolumn{4}{|l|}{ Clothing and footwear } \\
\hline Wearing apparel & -0.7244 & -1.0127 & -0.6569 \\
\hline Footwear & -0.6393 & -1.0294 & -0.7226 \\
\hline \multicolumn{4}{|l|}{ Chemicals and petrochemicals } \\
\hline Soap, detergents, toilet preparations and pharmaceuticals & -0.4128 & -0.9206 & -0.6636 \\
\hline Basic industrial chemicals, petroleum products and gases & -0.3725 & -0.6105 & -0.8439 \\
\hline Rubber Products & -0.3656 & -0.9322 & -0.8446 \\
\hline Plastic Products & -0.2532 & -2.7276 & -0.7636 \\
\hline \multicolumn{4}{|l|}{ Non-metallic } \\
\hline Structural clay products & -0.6674 & -0.4598 & -2.2201 \\
\hline \multicolumn{4}{|l|}{ Glass, cement and associated products } \\
\hline and other non-metallic products & -0.5761 & -0.6807 & -1.3793 \\
\hline \multicolumn{4}{|l|}{ Metals } \\
\hline Non-ferrous metal and iron and steel basic industries & -0.2449 & -0.9896 & -1.1814 \\
\hline Metal products, machinery and equipment & -0.2460 & -1.8269 & -0.8477 \\
\hline Electrical machinery, radio and commun ication equipment & -0.2436 & -3.8787 & -0.7651 \\
\hline \multicolumn{4}{|l|}{ Transport and other } \\
\hline Motor vehicles including reconditioning & -0.3897 & -2.1959 & -0.5825 \\
\hline Other manufacturing industries & -0.3724 & -1.8460 & -0.8005 \\
\hline Other vehicles and equipment & -0.2523 & -1.2041 & -1.5988 \\
\hline
\end{tabular}

Own-price elasticities are typically negative since prices and quantities change in opposite directions. Estimated own-price elasticities tend to become more elastic as the cost shares decline. This is consistent with the idea that as the quantities of an input demanded approach zero, the elasticity approaches infinity. On the other hand, higher fuel cost shares have more of an inelastic fuel price response.

Estimated results for own-price elasticities of demand lead to the following conclusions:

- The demand for electricity is price-inelastic ( $\eta_{E E}$ $<-1$ ) in most industries. The only elasticity esti- mates are reported for the Clothing and Footwear industries (with mean estimates of 0.72 for Wearing Apparel and -0.64 for Footwear) and for the Non-metallic industries (with mean estimates of -0.67 for Structural Clay Products and -0.58 for Glass, Cement and Associated Products). For the other industries, mean estimates range from -0.36 (Beverage and Tobacco industries) to -0.17 (Foodstuff industries).

- The demand for coal is price-elastic in most industries. High elasticity estimates $(\eta \mathrm{cc}>-1)$ are reported in the Metals Industries, the 
Table 4: Price elasticities of substitution

\begin{tabular}{|c|c|c|c|c|c|c|}
\hline & $\eta E C$ & $\eta_{C E}$ & $\eta_{E L}$ & $\eta_{L E}$ & $\eta_{C L}$ & $\eta_{\mathrm{LC}}$ \\
\hline \multicolumn{7}{|l|}{ Mining } \\
\hline Chrome & 0.0396 & 0.3875 & 0.2507 & 0.4911 & -1.0753 & -0.2151 \\
\hline Copper and nickel including smelting & 0.1224 & 0.5359 & 0.1001 & 0.4405 & -0.4557 & -0.4123 \\
\hline Gold & 0.0271 & 0.4439 & 0.1395 & 0.5493 & -1.7024 & -0.4097 \\
\hline Asbestos & 0.0467 & 0.5459 & 0.1115 & 0.5215 & -1.1734 & -0.4696 \\
\hline Other mining & 0.0126 & 0.1957 & 0.3067 & 0.4775 & -1.9595 & -0.1965 \\
\hline \multicolumn{7}{|l|}{ Foodstuffs } \\
\hline Slaughtering and processing of meat & 0.0093 & 0.0319 & 0.1198 & 0.3224 & -3.0919 & -2.4279 \\
\hline Canning and preserving fruit and vegetables & 0.0593 & 0.0619 & 0.1291 & 0.1507 & -1.4041 & -1.5697 \\
\hline Grain mill products and animal foods & -0.0792 & -0.2601 & 0.2673 & 0.3029 & -3.7737 & -1.3018 \\
\hline Chocolate and sugar confectionary & -0.0035 & -0.0062 & 0.1973 & 0.2408 & -2.1444 & -1.4511 \\
\hline Dairy and food products & 0.0375 & 0.0267 & 0.1039 & 0.0894 & -1.1513 & -1.3901 \\
\hline \multicolumn{7}{|l|}{ Beverages and tobacco } \\
\hline Beer, wine and spirits & 0.0761 & 0.1008 & 0.2826 & 0.3250 & 0.2453 & 0.2131 \\
\hline \multicolumn{7}{|l|}{ Tobacco products including post-auction } \\
\hline \multicolumn{7}{|l|}{ Textiles and cotton } \\
\hline \multicolumn{7}{|l|}{ Cotton, ginning, spinning, weaving } \\
\hline finishing textiles & 0.2502 & 0.6580 & 0.0694 & 0.2392 & -0.2438 & -0.3193 \\
\hline Knitted products, rope and cordage & 0.3243 & 0.5566 & 0.0687 & 0.1840 & -0.1281 & -0.1999 \\
\hline Other textile products & 0.2166 & 0.6303 & 0.1359 & 0.3077 & -0.2464 & -0.1916 \\
\hline \multicolumn{7}{|l|}{ Clothing and footwear } \\
\hline Wearing apparel & 0.1804 & 0.8593 & 0.5440 & 0.6202 & -0.5493 & -0.1314 \\
\hline Footwear & 0.1637 & 0.9519 & 0.4756 & 0.7029 & -0.6821 & -0.1734 \\
\hline \multicolumn{7}{|l|}{ Chemicals and petrochemicals } \\
\hline \multicolumn{6}{|l|}{ Soap, detergents, toilet preparations } & 0.6708 \\
\hline \multicolumn{7}{|l|}{ Basic industrial chemicals, petroleum products } \\
\hline and gases & 0.2604 & 0.1095 & 0.1121 & 0.0726 & 0.6977 & 1.0740 \\
\hline Rubber products & 0.1459 & 0.2560 & 0.2197 & 0.3067 & 1.0573 & 0.8411 \\
\hline Plastic products & -0.0491 & -1.1493 & 0.3023 & 0.4934 & 7.5603 & 0.5268 \\
\hline \multicolumn{7}{|l|}{ Non-metallic } \\
\hline Structural clay products & 0.3383 & 0.2128 & 0.3292 & 1.0126 & 0.1049 & 0.5129 \\
\hline $\begin{array}{l}\text { Glass, cement and associated products and } \\
\text { other non-metallic products }\end{array}$ & 0.1635 & 0.2155 & 0.4126 & 0.7435 & 0.2288 & 0.3127 \\
\hline \multicolumn{7}{|l|}{ Metals } \\
\hline Non-ferrous metal, iron, steel basic industries & 0.0321 & 0.0344 & 0.2388 & 0.2500 & 0.1793 & 0.1749 \\
\hline Metal products, machinery and equipment & -0.1635 & -0.5557 & 0.4104 & 0.3132 & 0.0341 & 0.0077 \\
\hline \multicolumn{7}{|l|}{ Electrical machinery, radio and communication } \\
\hline \multicolumn{7}{|l|}{ Transport and other } \\
\hline Motor vehicles including reconditioning & -0.2441 & -0.9912 & 0.6339 & 0.2602 & -2.6502 & -0.2680 \\
\hline Other manufacturing industries & -0.1239 & -0.5418 & 0.4947 & 0.3798 & -1.9415 & -0.3410 \\
\hline Other vehicles and equipment & 0.0634 & 0.1823 & 0.1890 & 0.5551 & -0.8739 & -0.8926 \\
\hline
\end{tabular}

Transport and Other Industries, Chemicals and Petroleum, Foodstuff Industries, Mining, and Clothing and Footwear Industries. Except for inelastic estimates in Beverages and Tobacco Industries and the Structural Clay Products in the Non-Metals Industries (with mean estimates of -0.35 and -0.46 , respectively), price-elastic estimates are obtained in the rest of the industries.
- The demand for liquid fuel is price-elastic in most industries. Inelastic estimates (with mean estimates of -0.35) are recorded for the Textile and Cotton Industries. High elasticity estimates $\left(\eta_{I I}>1.0\right)$ are found in the Non-Metals and Foodstuffs Industries.

The implication of these results is that small tax changes will induce decreases in consumption 
where the demand for energy is price-elastic. But, as in the case of electricity, large taxes are required for the demand of energy that is price-inelastic in order to achieve conservation targets. While this makes economic sense, it may not be politically feasible and one has balance it with the desired development objectives. The tax instrument can be used in dealing with policy objectives so as to reduce vulnerability caused by dependence on external sources of energy (i.e. liquid fuel) as well as environmental problems of energy consumption (as in the case of coal). Its advantage over other measures is that it relies on the pricing system and is therefore easily applicable. Authorities may also find it beneficial to use tax benefits in the form of energy-saving techniques.

These elasticity estimates are also dependent on other important factors that determine their values. For example, consider the issue of time period of adjustment to price changes. The longer the period of adjusting to price changes and availability of substitutes, the greater the chances of adjusting by altering demand for substitutes. But this, however, is also dependent on the affordability and availability of energy consuming technology for the substitutes.

We are also interested on what effect a tax measure on energy input $i$ has on input $j$. Cross-price elasticities of demand, $\eta_{i j}$ 's, yield useful information on substitution by measuring the proportionate change in energy input $i$ in response to the proportionate change in the price of input $j$, total energy being constant. Price changes should encourage greater efficiency of fuel use through substitution of one energy input by another. This may, for example, mean the replacement of fuel burning technology with more expensive but more efficient appliances. We impose the following restriction on our fuel share results $\eta_{i j} \div \eta_{j i}>0$ where an increase in the price of $i$ raises the consumption of $j$ and viceversa. This rules out $\eta_{i j}$ and $\eta_{j i}$ having opposite signs, a condition implicit in our symmetry conditions. Positive values of $\eta_{i j}$ or $\eta_{j i}$ indicate that the two fuels are substitutes, and negative values if they are complements. Because we are more interested in the substitution of liquid fuel with indigenous energy inputs (coal and electricity), we obtain the following cross-elasticity results (see Table 4):

- Although evidence appears slightly mixed, coal and liquid fuel are more of complements than substitutes in most industries. If the price of liquid fuel is increased by $1 \%$, this would imply a higher demand for coal in the following industries: Chemicals and Petrochemicals, Beverages and Tobacco, and in Non-Ferrous Metals and Metal Products (except for Electrical and Machinery). For these industries, coal and liquid fuel are substitutes. Results for the rest of the industries show that there is an inverse relation- ship between the price of liquid fuel and quantity demanded of coal.

- Evidence suggests that liquid fuels and electricity are substitutes in all industries. A $1 \%$ increase in the price of liquid fuel would result in higher demand for electricity in all industries. An overall picture is that electricity is more substitutable for liquid fuel for most industries with high crosselasticities in Clothing and Footwear followed by Mining.

The overall results on interfuel substitution suggest that if the price of liquid fuel was increased, this would result in a higher demand of electricity in all the industries, and in a higher demand for coal by some industries. Although the potential for interfuel substitution is evident, the adoption of alternative end-use devices and more efficient energy equipment has not been exploited in the immediate past because of constraints such as:

- the poor balance of payments performance resulting in severe cuts in the allocation of foreign exchange to industry;

- the depreciation of the Zimbabwe dollar and the high import tariffs raised costs as well as affordability of imported capital inputs; and

- the economic and financial constraints affecting industry such as world recession and slackening domestic demand.

\section{Conclusion}

Evidence suggests a potential for interfuel substitution in Zimbabwe industries. We find liquid fuel and electricity substitutes in all industries, and mixed results between coal and liquid fuel. Furthermore, as shown by positive price elasticities, there is considerable scope for improvement in energy efficiency in most industries. The implication of these results is that taxes and other financial incentives designed to encourage 'fuel-switching' should work if applied to industries where there is room for interfuel substitution.

To the extent that energy conservation is a goal of public policy, it is clear that the most effective policy instrument is the price of energy itself. Thus we have good reason to expect that the consumption of energy will be reduced if the price of energy is allowed to rise. If public authorities are really serious about reducing oil imports, then it is not only necessary to raise the price of liquid fuels, but also to address other issues that become a constraint to interfuel substitution such as the availability of foreign exchange to industry for the needed new equipment and spares, good management of the economy, and even tax incentives or tax relief in the form of energy -saving techniques and to encourage energy conservation. 


\section{Appendix}

\section{Estimation procedure}

From the existence of consistent estimates of $\rho_{i}$ in equation (4) we may utilise the Prais Winsten

Transform (see Greene, 1993) assuming $\rho_{i}$ is known.

For $t=1$

$$
\begin{aligned}
\bar{S}_{i k t} & =\sqrt{1-\rho_{i}^{2}} S_{i k t} \\
& =f_{i k} \sqrt{1-\rho_{i}^{2}}+\gamma_{i 1} \sqrt{1-\rho_{i}^{2}} \log \left(\frac{P_{11}}{P_{31}}\right)+\gamma_{i 2} \sqrt{1-\rho_{i}^{2}} \log \left(\frac{P_{21}}{P_{31}}\right)+v_{i k 1} \\
& =f_{i k} \bar{q}_{i 1}+\gamma_{i 1} \bar{P}_{i 11}+\gamma_{i 2} \bar{P}_{i 21}+v_{i k 1}
\end{aligned}
$$

For $t>1$,

$$
\begin{aligned}
\bar{S}_{i k t} & =S_{i k t}-\rho_{i} S_{i k t-1} \\
& =f_{i k}\left(1-\rho_{i}\right)+\gamma_{i 1}\left(\log \left(\frac{P_{1 t}}{P_{3 t}}\right)-\log \left(\frac{P_{1 t-1}}{P_{3 t-1}}\right)\right)+\gamma_{i 2}\left(\log \left(\frac{P_{2 t}}{P_{3 t}}\right)-\log \left(\frac{P_{2 t-1}}{P_{3 t-1}}\right)\right)+v_{i k t} \\
& =f_{i k} \bar{q}_{i t}+\gamma_{i 1} \bar{P}_{i 1 t}+\gamma_{i 2} \bar{P}_{i 2 t}+v_{i k t}
\end{aligned}
$$

Thus, we have introduced new explanatory variables:

$$
\begin{aligned}
& \bar{q}_{i t}=\left\{\begin{array}{cc}
\sqrt{1-\rho_{i}^{2}}, & t=1 \\
1-\rho_{i}, & t>1
\end{array}\right. \\
& \bar{q}_{i}=\left(\begin{array}{c}
\bar{q}_{i 1} \\
\bar{q}_{i 2} \\
\vdots \\
\bar{q}_{i T}
\end{array}\right), \\
& \bar{P}_{i}=\left(\begin{array}{cc}
\bar{P}_{i 11} & \bar{P}_{i 21} \\
\bar{P}_{i 12} & \bar{P}_{i 22} \\
\vdots & \vdots \\
\bar{P}_{i 1 T} & \bar{P}_{i 2 T}
\end{array}\right)
\end{aligned}
$$

To express model (1) in the form, $Y=X \beta+v$, we let $Y={ }_{i k t}\left(\bar{S}_{i k t}\right)$, where the indices are varied from right to left (first $t$, then $k$, and finally $i$ ).

Let $e_{r}^{\prime}=(1,1, \ldots, 1)$ denote the $r$-dimensional vector of ones and $I_{r}$ the $r$-dimensional identity matrix. The regression function for $i=1$ can be written

$$
\left(I_{H} \otimes \bar{q}_{1}\right)\left(\begin{array}{c}
f_{11} \\
f_{12} \\
\vdots \\
f_{1 / I}
\end{array}\right)+\left(e_{H} \otimes \bar{P}_{1}\right)\left(\begin{array}{c}
\gamma_{11} \\
\gamma_{12}
\end{array}\right)
$$

and correspondingly for $i=2$. Hence, the full model can be written (the zeros denoting zero-matrices) 


$$
Y=\left(\begin{array}{cccc}
\left(I_{I I} \otimes \bar{q}_{1}\right) & \left(e_{H} \otimes \bar{P}_{1}\right) & 0 & 0 \\
0 & 0 & \left(I_{I I} \otimes \bar{q}_{2}\right) & \left(e_{I I} \otimes \bar{P}_{2}\right)
\end{array}\right)\left(\begin{array}{c}
f_{11} \\
\vdots \\
f_{I I I} \\
\gamma_{11} \\
\gamma_{12} \\
f_{21} \\
\vdots \\
f_{2 H} \\
\gamma_{21} \\
\gamma_{22}
\end{array}\right)+v
$$

In the equation above, $v$ is normally distributed with $\mathrm{E}(v)=0$ and covariance matrix, $\operatorname{cov}(v)=\Omega \otimes I_{T H}$, where

$$
\Omega=\operatorname{cov}\left(\begin{array}{l}
v_{1 k t} \\
v_{2 k t}
\end{array}\right)=\left(\begin{array}{ll}
\omega_{11} & \omega_{12} \\
\omega_{12} & \omega_{22}
\end{array}\right)
$$

We develop a 'feasible generalised least squares' (FGLS) estimator in three steps.

\section{Step 1}

We follow Greene in estimating $\rho_{1}$ and $\rho_{2}$. For each combination $(i, k), \rho_{i}$ is estimated from the residuals of the ordinary least squares (OLS) estimator of (4). We show the result as $r_{i k}$ and denote the residuals as $e_{i k t}$, where $t=1, \ldots, T$,

$$
r_{i k}=\frac{\sum_{t=2}^{T}\left(e_{i k t} e_{i k, l-1}\right)}{\sum_{t-1}^{T} e_{i k t}^{2}}
$$

The $r_{i 1}, \ldots, r_{i l l}$ are all consistent, asymptotically normal estimation for $\rho_{i}$ with asymptotic variance

$$
\frac{1-\rho_{i}^{2}}{T}
$$

We then let

$$
\hat{\rho}_{i}=\frac{1}{H} \sum_{k=1}^{H} r_{i k}
$$

with asymptotic variance

$$
\operatorname{var}\left(\hat{\rho}_{i}\right)=\frac{1-\rho_{i}^{2}}{H T}
$$

From this, we get an approximate 95 percent confidence interval for $\rho_{i}$ :

$$
\hat{\rho}_{i} \pm 1.96 \sqrt{\frac{1-\hat{\rho}_{i}^{2}}{I I T}}
$$

If this interval lies entirely on the positive axis, not covering zero, then $\hat{\rho}_{i}$ is significantly (5\%) larger than zero. 


\section{Step 2}

Having obtained consistent estimates for $\rho_{i}$ we may assume $\rho_{i}$ known and calculate $\bar{q}_{i}, \bar{P}_{i}$ and $Y=\left(\bar{S}_{i k t}\right)$. We obtain consistent estimate of

$$
\Omega=\left(\begin{array}{ll}
\omega_{11} & \omega_{12} \\
\omega_{12} & \omega_{22}
\end{array}\right)=\operatorname{cov}\left(\begin{array}{l}
v_{1 k t} \\
v_{2 h t}
\end{array}\right), \quad \text { for all }(k, t)
$$

by running OLS separately on the two blocks of $Y$ defined by $i=1,2$

$$
Y_{i}=X_{i} \beta_{i}+v_{i}
$$

where

$$
X_{i}=\left(I_{H} \otimes \bar{q}_{i}, e_{I I} \otimes \bar{P}_{i}\right)
$$

If $\tilde{v}_{i}$ denotes the residual vectors, we get

$$
\hat{\omega}_{i j}=\frac{1}{H T} \widetilde{v}_{i}^{\prime} \tilde{v}_{j} \quad \text { for } i, j=1,2
$$

\section{Step 3}

The unrestricted (i.e. without symmetry $\gamma_{i j}=\gamma_{j i}$ ) FGLS estimator for $\beta$ is

$$
\hat{\beta}=\left[X^{\prime}(\operatorname{covv}(v))^{-1} X\right]^{-1} X^{\prime}(\operatorname{covv}(v))^{-1} Y
$$

where

$$
\operatorname{cov}(v)=\hat{\Omega} \otimes I_{H T}
$$

By expressing

$$
\hat{\Omega}^{-1}=\left(\begin{array}{ll}
\hat{\omega}^{11} & \hat{\omega}^{12} \\
\hat{\omega}^{12} & \hat{\omega}^{22}
\end{array}\right)
$$

we can write $\hat{\beta}$ more compactly as

$$
\hat{\beta}=\left[\begin{array}{ll}
\hat{\omega}^{11} X_{1}^{\prime} X_{1} & \hat{\omega}^{12} X_{1}^{\prime} X_{2} \\
\hat{\omega}^{21} X_{2}^{\prime} X_{1} & \hat{\omega}^{22} X_{2}^{\prime} X_{2}
\end{array}\right]^{-1}\left[\begin{array}{l}
\hat{\omega}^{11} X_{1}^{\prime} Y_{1}+\hat{\omega}^{12} X_{1}^{\prime} Y_{2} \\
\hat{\omega}^{21} X_{2}^{\prime} Y+\hat{\omega}^{22} X_{2}^{\prime} Y_{2}
\end{array}\right]
$$

A consistent estimate of the covariance matrix of $\hat{\beta}$ is then

$$
\operatorname{côv}(\hat{\beta})=\left(X^{\prime} \operatorname{cov}(v)^{-1} X\right)^{-1}=\left[\begin{array}{ll}
\hat{\omega}^{11} X_{1}^{\prime} X_{1} & \hat{\omega}^{12} X_{1}^{\prime} X_{2} \\
\hat{\omega}^{12} X_{2}^{\prime} X_{1} & \hat{\omega}^{22} X_{2}^{\prime} X_{2}
\end{array}\right]^{-1}
$$




\section{References}

Berndt, E.R. and Christensen, L.R 1973a. The internal Structure of Functional Relationships: Separability, Substitution and Aggregation. Review of Economic Studies, Vol. 40, July.

Berndt, E.R. and Christensen, L.R 1973b. The Translog Function and the Substitution of Equipment, Structure and Labour in US Manufacturing 1929 1968. Journal of Econometrics, March.

Christensen, L.R., Jorgensen, D.W., and Lau, L.T 1971. Conjugate Duality and the Transcendental Logarithmic Function. Econometrica, 39.

Christensen, L.R., Jorgensen, D.W., and Lau, L.T 1973. Transcendental Logarithmic Production Frontier. Review of Economics and Statistics, 55.

Diewert, W.E 1971. An Application of the Shephard Duality Theorem: A Generalized Leontief Production Function. Journal of Political Economy, 79.

Diewert, W.E 1973. Separability and a Generalization of the Cobb-Douglas Cost, Production, and Indirect Utility Functions. Working Paper, University of British Columbia.

Diewert, W.E 1974. Applications of Duality Theory, (ed) M, Intriligator and D Kendrick, Frontiers of Quantitative Economics II, Amsterdam, North Holland.

Field, B.C. and Allen, P.G1980. Substitution for Energy in US Manufacturing. Review of Economics and Statistics, Vol. 62.

Green, H.A.J 1964. Aggregation in Economic Analysis. An Introductory Survey, Princeton, New Jersey, Princeton University Press.

Greene, W.H 1993. Econometric Analysis, Macmillan Publishing Company.

Griffin, J.M 1977. Interfuel Substitution Possibilities: A Translog Application to Pooled Data. International Economic Review, 18.

Magnus, J and Woodland, A. D 1980. Interfuel Substitution Possibilities in Dutch Manufacturing: An Error Components Approach'. Discussion Paper No. 80-39, Department of Economics, University of British Columbia.

Mundlak, Y 1978. On Pooling of Time-Series and CrossSection Data. Econometrica.

Pindyck, R 1979. The Structure of World Energy Demand, The MIT Press.

Uri, N 1982. The Demand for Energy in the U K. Bulletin of Economic Research, Vol. 34 No. 1.

Uzawa, H 1962. Production Functions with Constant Elasticities of Substitution. Review of Economic Studies. 